\title{
Rekonstruksi Kisah Nabi Musa dalam al-Quran: Studi Perbandingan dengan Perjanjian Lama
}

\author{
Syukron Affani \\ (STAIN Pamekasan Jln. Raya Panglegur Km. 04 Pamekasan, email: \\ syukron.affani@stainpamekasan.ac.id)
}

\begin{abstract}
Abstrak:
Rekonstruksi kronologis kisah Nabi Musa dalam al-Quran ini, ditujukan untuk mengetahui alur bercerita al-Quran secara umum dan bukan dari sisi gaya ceritanya (al-fann al-qashashi). Tulisan ini tidak mengarahkan fokusnya pada aspek linguistik tetapi perunutan cerita untuk kepentingan komparasi dengan teks di luar al-Quran (Perjanjian Lama). Metodenya adalah pertama, mengumpulkan seluruh ayat yang berisi tentang cerita Nabi Musa; kedua, merekonstruksi ayat-ayat terkumpul dalam satu alur kisah dan membabakkannya; ketiga, menerjemahkan ayat-ayat tersebut dengan lebih terbuka dalam suatu deskripsi-narasi yang bertutur. Metode yang sama juga ditempuh pada Perjanjian Lama. Secara tehnis, kisah Nabi Musa dalam Perjanjian Lama lebih mudah dikonstruksi daripada kisah Nabi Musa dalam al-Quran karena dalam Perjanjian Lama, kisah Nabi Musa diceritakan dengan gamblang terutama di dalam Kitab Keluaran (exodus). Hasil perbandiangan menunjukkan perbedaan-perbedaan kisah Nabi Musa di dalam al-Quran dan Perjanjian Lama terutama dari sisi detail cerita. Dalam disiplin ilmu al-Quran, narasi Perjanjian Lama tentang Nabi Musa merupakan sumber israiliyat yang polemis.
\end{abstract}

\section{Kata-kata Kunci: \\ Rekonstruksi Kisah, Musa, Perjanjian Lama, Bani Israil}

\begin{abstract}
:
The chronological reconstruction of the story of Moses in the Qur'an is intended to know the storyline of the Qur'an in general and not the story style (al-fann al-qashashi). This paper does not focus on the linguistic aspect of the story but on the story's narrative for comparative purposes with text outside the Qoran (Old Testament).This is done through; first, collecting all the verses that contained the story of Prophet
\end{abstract}


Moses; Second, reconstructing the collected verses in one storyline and putting them in some episodes; Third, translating the verses more overtly in a descriptive-narrative story. The same method is also applied to the Old Testament. Technically, the story of Moses in the Old Testament seems to be easier to construct than the story of Moses in the Quran because the story of the prophet Moses is narrated clearly in the Old Testament especially in the Exodus.The result of the comparison shows differences between the story of Moses in the Qur'an and the story narrated in the Old Testament, especially in terms of the details of the story. In the discipline the science of Quran, the Old Testament narrative of Moses is a polemical source of israiliyat.

\section{Key Words:}

Reconstruction of a Story, Moses, Old Testament, The Children of Israel

\section{Pendahuluan}

Gaya berkisah al-Quran (taqshish al-Quran) concern pada tujuan tersirat untuk memberikan petunjuk moral, peringatan, hikmah dan terutama ajaran tauhid. Kisah yang ditampilkan oleh al-Quran bukan untuk mengungkapkan data-data faktual dalam kisah-kisah itu melainkan menyampaikan hikmah-hikmah yang dapat memperkokoh dakwah Islamiyah. Selebihnya, yang berhubungan dengan konteks utuh kisah, diperlukan telaah kesejarahan melalui buku-buku sejarah atau kitab-kitab tafsir yang tidak sedikit merujuk pada literatur-literatur Israiliyyat. ${ }^{1}$

Perlu ditegaskan bahwa al-Quran memang bukan kitab sejarah tetapi kitab hikmah dan kitab hidayah yang menggunakan, salah satunya, sejarah sebagai sarana komunikasinya. Meski demikian, sejarah dalam kisah-kisah al-Quran bukan fiksi tetapi kisah yang sudah populer di kalangan umat agama samawi sebelumnya. Kecuali beberapa saja, kisah-kisah dalam al-Quran telah menjadi pengetahuan umum di kalangan penganut agama-agama samawi: Yahudi dan Nasrani. Contoh kisah Nabi Musa, kisah yang paling

\footnotetext{
${ }^{1}$ Muhammad Qutb, al-Qishshah fi al-Quran: Maqashid al-Dien wa Qiyam al-Fann, (Dar Qubba': Kairo, 2002), 277-294
} 
banyak dimuat dalam al-Quran. ${ }^{2}$ Jauh sebelum al-Quran menyinggung kisahnya, orang-orang Yahudi dan Nasrani sudah terlebih dahulu mengetahuinya karena Nabi Musa adalah ikon bani Israil.

Oleh karena itu, menarik untuk memperbandingkan khazanah kisah dalam al-Quran dengan kisah yang sama yang ada dalam sumber-sumber Yahudi-Nasrani. Meskipun berasal dari akar yang sama, tetapi ketiga agama yang tokoh-tokoh (Nabi dan rasul) nya identik ini, selalu berada dalam ketegangan-ketegangan teologis, sosiologis, dan politik.

Membaca kisah Nabi Musa langsung dari al-Quran memerlukan upaya lebih untuk memahaminya. Sebab, seperti kebanyakan kisah dalam al-Quran, kisah Musa dalam al-Quran terpencar-pencar, dengan gaya dan logika bahasa yang berbeda-beda dalam kemasan sastrawinya, diulang-ulang ditempat-tempat yang berbeda dengan kronologi yang acak, dan mengabaikan keterpaduan unsur kisah (termasuk nama tokoh, waktu, serta tempat). ${ }^{3}$

Merekonstruksi kisah Musa dalam al-Quran, ditujukan untuk membangun alur cerita al-Quran secara umum bukan menelaah dari sisi susastrawinya (al-fann al-qashashî). Tulisan ini untuk merunut

2 M. Faisol, "Interpretasi Kisah Nabi Musa Perspektif Naratologi al-Quran” dalam Jurnal ISLAMICA: Jurnal Studi Keislaman, Vol. 11, No. 2, Maret 2017, 366

3 Pengabaian plot, alur, subjek, dan akurasi data memang disengaja, sebab al-Quran hanya fokus pada unsur tertentu yang dipilihnya, yaitu tema. Mayoritas kisah-kisah al-Quran tergolong ayat-ayat Makkiyah dengan isu sentral 3 hal : ketuhanan, kerasulan, dan mukjizat. Muhammad Aḥmad Khalafullâh, al-Fann al-Qashashî fi alQurân al-Karîm, (Sina: Londōn-Beirut-Kairo, 1999), 131, 283, dan 299. Muhammad Ahmad Khalafullah adalah nama kontroversial saat menyatakan dalam disertasi doktoralnya bahwa al-Quran tidak dapat dijadikan sebagai referensi sejarah par excellent. Mayoritas ulama puritan menolak pandangan tersebut. Dengan pernyataannya tersebut, mereka menilai bahwa Khalafullah telah menganggap kisahkisah dalam al-Quran adalah tidak historis atau khoyyâl (ilusi-imajinatif) atau paling tidak bercampur dengan imajinasi kesusastraan. Hal itu bertolak belakang dengan keyakinan umat Islam tentang validitas dan akurasi al-Quran yang tak dapat ditawar-tawar karena merupakan sesuatu yang berasal dari Yang Haqq; Yang Mahabenar. Manna' Khalil al-Qatthan, ulama Saudi Arabia yang kitab studi alQurannya menjadi salah satu rujukan pokok di berbagai perguruan tinggi Indonesi, termasuk yang menyayangkan pandangan Muhammad Ahmad Khalafullah. Lihat Mannâ' Al-Qatthân, Mabâhits fi Ulûm al-Quran, (Riyâdh: Mansyûrât al-'Âshr alHadîts, 1973), 308 
cerita Nabi Musa dengan mengkomparasi antara al-Quran dan Perjanjian Lama (selanjutnya disebut, PL). Dengan demikian, metodenya adalah pertama, mengumpulkan seluruh ayat tentang Nabi Musa; kedua, merekonstruksi ayat-ayat terkumpul dalam satu alur kisah dan membabakkannya; ketiga, menerjemahkan ayat-ayat tersebut dalam suatu deskripsi-narasi yang bertutur untuk mendapatkan ilustrasi yang hidup. Metode yang sama juga ditempuh pada PL dan secara tehnis lebih mudah daripada penerapannya terhadap al-Quran karena dalam PL, kisah Nabi Musa diceritakan lengkap terutama dalam Kitab Keluaran (Exodus).

Kisah Nabi Musa dalam al-Quran sendiri tersebar dalam 30 surat dan termasuk kisah yang paling banyak dimuat dalam alQuran. Ada beberapa surat yang lengkap menerangkan kisah sosok sentral dalam agama Yahudi ini. Selebihnya, hanya potonganpotongan kisah dalam satu dua ayat saja. Surat-surat yang cukup representatif menggambarkan kisah Nabi Musa adalah Q.S al-A'räf, al-Kahfi, Thāha, as-Syu'arâ', dan al-Qashash. Sedangkan surat-surat yang repetitif, segmentatif (sepotong-sepotong), dan global mengisahkan Nabi Musa adalah Q.S al-Baqarah, Āli Imran, al-Māidah, Yünus, Ibrahim, al-Isra, al-Hajj, al-Mukminūn, al-Furqān, al-Naml, alAnkabūt, al-Mukmin, al-Dukhkhan, al-Shaff, dan al-Nāziat.

\section{Masa Kecil Musa (al-Quran) dalam al-Quran ${ }^{4}$ dan Perjanjian Lama ${ }^{5}$}

Masa kecil Musa ${ }^{6}$ dimulai dalam Q.S al-Qashash.7 Seorang ibu yang memiliki bayi bernama Musa kuatir dengan situasi keamanan di Mesir yang mengancam nyawa setiap bayi laki-laki. Allah memberikan ilham kepada ibu Musa untuk menghanyutkan Musa

\footnotetext{
${ }^{4}$ Rekonstruksi kisah Musa ini memanfaatkan jasa software DivineIslam's Qur'an Viewer software v2.913 by Jamal Nashir dan Digital Quran ver.3.2 tahun 2003-2004 by Sony Sugema. Kisah Nabi Musa perspektif umat Islam dapat dibaca secara lengkap dalam: Abû al-Faraj `Abd al-Rahmân bin `Alî bin Muhammad bin Ibn al-Jawzi, al-Muntadham fi Târikh al-Muluk wa al-Umam, Jilid 1, (Dâr al-Kutub al-Ilmiyah: Beirut, 1992), 331 hingga 379

${ }^{5}$ Pelacakan menggunakan jasa software Program alKitab v. 2.7 (1999-2000) by J.F Kassenda

${ }^{6}$ Nama lengkapnya Musa bin Imron bin Qahits bin Lawi bin Ya'qub. Ibunya bernama Yukhabid. Konon jarak hidup Nabi Musa dengan Nabi Ibrahim adalah seribu tahun, sama dengan jarak Nabi Ibrahim dengan Nabi Nuh dan Nabi Nuh dengan Nabi Adam. Lihat Ibn al-Jawzi, al-Muntadham, 331

${ }^{7}$ Q.S al-Qashash 28:4-14
} 
secara aman (dimasukkan ke peti) ke sungai Nil. Ibu Musa diilhami agar tidak kuatir karena Musa akan kembali berada dalam pengawasannya dan kelak akan menjadi orang pilihan. Ketika terombang-ambing di sungai Nil, Musa ditemukan oleh perempuannya Firaun (imro'ah fira'un). Dayang-dayang istri Firaun atau istri Firaun sendiri. Begitu melihat Musa, istri Firaun merasakan ketertarikan yang kuat. Ia meminta kepada Firaun agar tidak membunuh bayi itu. Bahkan istri Firaun meminta kepada Firaun agar diperkenankan mengangkat Musa sebagai anak. Firaun tidak menyadari bahwa bayi yang ditakutinya justru kini menjadi anak kesayangan istrinya.

Kisah Musa dalam PL banyak diterangkan terutama dalam kitab Keluaran. Dikisahkan bahwa Musa berayah ibu bani Lewi. Dalam PL tidak disebutkan sebab musabab langsung bayi Musa harus dihanyutkan ke sungai Nil. Yang menemukan bayi Musa adalah puteri firaun yang sudah dapat menduga kalau bayi itu adalah bayi Ibrani. Ketika bayi itu dihanyutkan, kakaknya mengawasi dari jauh ${ }^{8}$ (pada bagian ini hingga sang kakak berhasil menyusukan Musa pada ibu kandungnya, identik dengan al-Quran). Puteri Firaun itulah yang mengangkat bayi Musa menjadi anak dan memberinya nama Musa dengan arti: "ditarik dari air". 9

\section{Menjelang Dewasa: Petaka Pembunuhan dan Pelarian ke Madyan (al-Quran) ${ }^{10}$}

Di suatu tempat di kota (konon, Memphis), Musa menemukan dua laki-laki (bani Israil dan suku pribumi Qibti) sedang berkelahi. Musa menolong laki-laki bani Israil sehingga orang Mesir itu mati. Musa menyesali tindakannya itu sebagai perbuatan setan.

Musa pun bersembunyi. Keesokan harinya, Musa bertemu dengan orang bani Israel yang kemarin dibantunya. Musa menghardik laki-laki bani Israel itu. Tetapi laki-laki itu menyalahkan Musa, "Musa, apakah kamu mau membunuhku, padahal kemarin kamu sudah membunuh orang? Kamu memang sewenang-wenang

\footnotetext{
${ }^{8}$ Keluaran (Kel.) 2:4

9 Penjelasan mengenai bayi Musa terdapat dalam Kel. 2:1-10

10 Q.S al-Qashash 28:15-20
} 
dan tidak menginginkan perdamaian." Tiba-tiba muncul seseorang yang memberitahunya agar segera meninggalkan kota.

Musa meninggalkan Mesir. Ia terus berjalan jauh menuju daerah Madyan. ${ }^{11}$ Tiada hentinya Musa berdoa memohon perlindungan Allah dari pejabat-pejabat Mesir yang tidak akan membiarkannya begitu saja, meskipun ia sendiri anak angkat Firaun. Sebab orang yang dibunuhnya tanpa sengaja adalah orang Mesir asli. ${ }^{12}$ Di sebuah kawasan di Madyan, Musa berhenti di suatu sumber air minum yang ramai dengan orang-orang menggembala ternak. Musa memperhatikan dua orang gadis yang sedang berusaha mengendalikan ternak-ternaknya. Musa melihat ada yang ganjil dengan dua gadis itu. ${ }^{13}$

Musa bertanya dan dijawab oleh kedua gadis tersebut, "Kami tidak dapat memberi minum ternak kami sebelum pengembalapengembala laki-laki itu selesai. Sedang bapak kami adalah orang tua yang telah lanjut usia." Musa merasa iba. Walaupun dalam keadaan payah, ia membantu kedua gadis itu lekas-lekas memberi minum ternaknya. Setelah selesai, Musa kembali berteduh untuk beristirahat. Ia sendiri sebenarnya sebatang kara dan membutuhkan pertolongan. Musa berdoa kepada Allah.

Tidak lama berselang, gadis yang ditolong Musa datang dan meminta Musa menemui ayahnya. Ia menemui bapak dua gadis itu yang tak lain adalah Nabi Syuaib. Setelah beramah-tamah sekedarnya, Musa mulai menceritakan siapa dirinya dan apa yang sedang terjadi menimpanya. Mendengar semuanya, Nabi Syuaib berkata, "Kamu tidak perlu takut. Kamu telah jauh dan selamat dari orang-orang yang dzalim itu." 14

\footnotetext{
11 Negeri Madyan ini terletak di arah tenggara dan jauh dari Memphis, Ibu kota kekuasaan Firauan. Sedikit ke arah timur dari Madyan adalah wilayah Tabuk. Syauqi Abu Khalil, Athlas al-Quran, (Dar al-Fikr: Damaskus, 2003), 77

12 Menurut beberapa ahli sejarah muslim, firaun sendiri diindikasikan bukan orang Mesir asli. Dinasti firaun adalah suku Amalek dari Syria yang tertarik menguasai Mesir karena penguasanya adalah seorang ratu. Raja Amalek, Walid bin Duma menyerbu dan menaklukkan Mesir. Ia kemudian diganti raja Amalek yang lain, Kayyan bin Walid yang sejaman dengan Yusuf. Ibn Khaldun berpendapat bahwa firaun pada jaman Ibrahim, Yusuf, dan Musa adalah orang-orang Amalek. Muzaffaruddin Nadvi, Sejarah Geografi al-Quran, (Pustaka Firdaus:Jakarta, 1997),. 105 ${ }_{13}$ Q.S al-Qashash 28:21-24

14 Ibid., 25-28
} 
Dua gadis putri Syuaib mengajukan usul kepada ayahnya agar mempekerjakan Musa karena ia pemuda yang kuat dan dapat dipercaya." Syuaib memiliki rencana bagus untuk Musa. Syuaib mendiskusikan rencana masa depan Musa untuk menikahkan Musa dengan salah satu putrinya. Syaratnya, bekerja kepada Nabi Syuaib selama 8-10 tahun. Musa agak keberatan dengan syarat waktu itu tetapi ia merasakan niat baik Syuaib. Ia bersedia memenuhi syarat tersebut dengan Allah sebagai saksinya.

\section{Pembunuhan dan Pelarian ke Midian (PL)}

Ketika Musa dewasa (konon berusia 18 tahun), ia keluar untuk melihat kerja paksa terhadap bani Israel. Di suatu tempat yang sepi, ia melihat dua orang berkelahi dari bani Israel melawan orang Mesir. Musa membantu orang Bani Israel membunuh lawannya dan menyembunyikan mayatnya dalam pasir. Esok harinya, Musa melihat dua orang Israel saling berkelahi. Musa bermaksud melerainya tetapi keduanya mengira Musa akan membunuh salah seorang dari mereka seperti kemarin. Musa terkejut mengetahui ada orang yang mengetahui tindakan pembunuhannya. Musa bahkan mendengar rencana firaun yang akan menghukumnya. Musa menyelamatkan diri menuju Midian. ${ }^{15}$

Di Midian Musa berkesempatan membantu tujuh orang gadis gembala yang hendak memberi minum ternaknya dan diganggu penggembala-penggembala yang lain. Ketujuh gadis itu adalah puteri-puteri Yitro. Salah satu puteri Yitro, Rehuellah Zipora akhirnya dinikahkan dengan Musa. Bersama puteri Yitro ini, Musa mendapatkan keturunan bernama Gersom (si pendatang asing). ${ }^{16}$

\section{Momen Sinai Pertama: Perjalanan Kembali ke Mesir (al-Quran) ${ }^{17}$}

Setelah mengabdi kepada Nabi Syuaib selama 8-10 tahun, Nabi Musa ingin menjenguk ke Mesir. Nabi Musa turut serta membawa

${ }^{15}$ Kel. 2:11-15 bandingkan dengan Q.S al-Qashash 28:15-20

16Kel. 2:16-22. Yitro dalam Islam adalah Syuaib. Yitro dituturkan berputri 7 orang. Dalam al-Quran, Syuaib diceritakan berputri 2 orang (Q.S al-Qashash 28:23, imroataini tadzudzani).

17 Q.S Thaha 20:9-97 
keluarganya untuk suatu perjalanan yang panjang itu. ${ }^{18}$ Di suatu lembah di Thur Sinai ${ }^{19}$, Nabi Musa melihat titik api di kejauhan. Nabi Musa akan pergi ke titik api itu dengan harapan memperoleh sesuatu yang berguna. Di dekat titik api itu, Musa mendengar panggilan suara, "Hai, Musa." Musa mencari sumber panggilan. "Aku inilah Tuhanmu. Lepaskanlah kedua terompahmu di lembah yang suci, Thuwa ini." Musa melepaskan sandalnya. Kemudian Allah menurunkan maklumat keNabian dan kerasulan kepada Nabi Musa.

Sebagai salah satu tanda kerasulan, Musa diberi mukjizat berupa tongkat. ${ }^{20}$ Di samping mukjizat tongkar itu, Allah menunjukkan salah satu mukjizat yang lain. "Jepitkanlah tanganmu ke dalam saku bajumu, niscaya tanganmu akan menjadi putih cemerlang tanpa cacat. Inilah sebagian kekuasaan-Ku yang agung yang Aku berikan kepadamu."21 Nabi Musa dikarunia sembilan mukjizat (tis'a âyâh bayyinâh, Q.S al-Isra' 17:101). Sembilan mukjizat itu dirinci yaitu tongkat, tangan, belalang, kutu, katak, darah, taupan, laut, dan ayat-ayat perintah. ${ }^{22}$

\section{Momen Sinai Pertama (PL)}

Suatu ketika, Musa menggembala hingga ke gunung Horeb. Musa heran melihat semak yang menyala tetapi tidak terbakar. Ia memeriksanya, dan di sanalah ia diseru oleh Allah untuk pertama

18 Panjang karena memutar dan mengitari gurun sinai melalui Thur di selatan. Sedangkan saat pelarian sebelumnya dari Mesir, Nabi Musa melewati jalur lurus di utara di Gunung Hur. Lihat Syauqi Abu Khalil, Athlas al-Quran..., 77

${ }^{19}$ Q.S Thaha 20:11-23. Lihat juga Q.S al-Naziat 15-25 yang menceritakan secara garis besar kisah Musa sejak perintah di lembah Thuwa Thur Sinai untuk menghadapi Firaun hingga diazabnya Firaun akibat pengakuannya sebagai Tuhan, sesuatu yang disurat-surat lain digambarkan sebagai tindakan yang melampaui batas.

${ }^{20}$ Surat an-Naml juga menceritakan episode kunjungan Musa yang pertama di Thur Sinai. Di situlah Allah menurunkan sembilan mukjizat yang akan menjadi bekal melawan Firaun (Q.S al-Naml 27:12). Salah satu mukjizat itu adalah tongkat Musa yang berubah menjadi ular. Musa lari ketakutan tanpa menoleh ke belakang (Q.S alNaml 27:10). Allah menegur Musa karena tindakannya tidak layak untuk seorang rasul. Di samping itu, mukjizat yang lain adalah tangan Musa mengeluarkan cahaya setelah dimasukkan ke saku bajunya (Q.S al-Naml 27:12)

21 Thaha 20:22 dan an-Naml 27:12

22 Pendapat Ibnu Abbas dalam Imad al-Din Abu al-Fida' Ismail bin Katsir alDimasyqi, Tafsir al-Quran al-'Adzim, Jilid 9, (Beirut: Maktabah al-Nûr al-Ilmiyah, 1992), 87 
kalinya. Pada kesempatan itu, Musa mendapatkan mandat perintah untuk membebaskan bani Israel di Mesir dari cengkraman firaun. Musa mendapatkan bekal-bekal tuntunan untuk mendekati firaun agar bersedia memberikan kelonggaran beribadah kepada bani Israel di Mesir. ${ }^{23}$ Dikabarkan juga kepada Musa bahwa firaun yang hendak menghukumnya telah mati. Artinya, kini ia menghadapi firaun penerus firaun sebelumnya. ${ }^{24}$ Perintah yang paling jelas kepada Musa adalah membebaskan bani Israel dari perbudakan firaun agar leluasa beribadah kepada Allah. ${ }^{25}$ Tidak ada perintah khusus untuk juga mengajak firaun bertauhid dan bertobat seperti dalam al-Quran.

Musa kuatir dengan perintah itu. Ia berdalih tak lihai berdalil karena lidahnya kelu. Hal itu membangkitkan amarah Tuhan. Musa memohon agar didampingi Harun, kakaknya (usia mereka berselang tiga tahun ${ }^{26}$ dan Allah mengabulkannya. Untuk kepentingan misi liberasi bani Israel itu, Musa dibekali tongkat ajaib, tangan berkuman penyakit kusta, dan menjadikan air menjadi darah. ${ }^{27}$

\section{Membebaskan Bani Israel dan Menghadapi Firaun (al-Quran) ${ }^{28}$}

Perintah Allah kepada Musa telah diturunkan. Tetapi Musa merasa takut (karena pernah membunuh orang Mesir) dan tidak percaya diri sehingga meminta Harun yang pandai orasi untuk diangkat sebagai orang yang membantu perjuangannya. ${ }^{29}$ Permintaan Musa dikabulkan oleh Allah.

Musa dan Harun diperintahkan oleh Allah agar berbicara dengan lemah-lembut agar Firaun bersedia mengikuti ajakan keduanya. ${ }^{30}$ Allah menjamin Musa dan Harun dengan pertolonganNya sehingga keduanya tidak perlu kuatir menghadapi

\footnotetext{
${ }^{23}$ Kel. 3:1-23

${ }^{24}$ Kel. 2:23 dan Kel. 4:19

${ }^{25}$ Kel. 4:18-21

26 Kel. 7:7

27 Kel. 4:1-14

${ }^{28}$ Mengenai hal ini selain Q.S Thaha, Q.S Ad-Dukhan (17-31) juga menerangkan meski serba singkat. Dalam surat ini, dijelaskan mengenai kedatangan Musa untuk menyeru kepada Firaun dan kehancuran Firaun yang tenggelam ke dasar lautan meninggalkan kemegahan dunia yang mereka bangga-banggakan. Demikan adalah siksa Allah bagi Firaun yang sombong dan telah melampaui batas.

${ }^{29}$ Q.S al-Qashash 28:33-35

${ }^{30}$ Q.S Thaha 20:44
} 
Firaun. Atas nama Rasul Allah, keduanya menghadap Firaun dan segera meminta agar bani Israel dibebaskan dari belenggu Firaun.

Betapa Firaun heran atas tindakan Musa yang pernah diasuhnya dan kini berdiri untuk menentangnya. Firaun menganggap Musa tidak tahu balas budi. Namun, Musa tidak menyesal sebab menurutnya, apa yang terjadi pada masa lalunya adalah kecelakaan dan kekhilafannya. Musa menuduh dengan sinis kepada Firaun bahwa perhatian kepadanya yang melimpah dulu adalah kedok untuk menutupi kejahatan perbudakannya kepada bani Israel. ${ }^{31}$

Firaun bertanya siapakah Tuhan Musa dan Harun. Musa menjawab, "Tuhan kami ialah Tuhan yang telah menciptakan alam raya ini lengkap dengan isi dan aturannya." Firaun tergelak dan berteriak kepada orang-orang sekelilingnya. ${ }^{32}$ Firaun menanggapi dengan angkuh, "Wahai kaumku, tidak ada Tuhan bagimu selain aku. Haman! bakarlah untukku tanah liat, kemudian buatkan bangunan yang tinggi supaya aku dapat naik melihat Tuhan Musa. Aku benarbenar yakin bahwa dia pendusta." ${ }^{33}$ Musa tetap mempersuasi Firaun agar beriman kepada Allah. ${ }^{34}$

Tetapi Firaun tetap tidak percaya dan mengancam Musa. Nabi Musa terus berupaya meyakinkan Firaun dengan bukti-bukti mukjizat. Namun, Firaun tetap tidak bergeming. Bahkan Firaun menuduh Musa hendak melakukan tindakan kudeta terhadap Firaun. Firaun tidak mau kehilangan muka dan menantang Musa menentukan waktu untuk menggelar adu kekuatan antara Musa dengan Firaun. Musa menerima tantangan itu. ${ }^{35}$

Akan tetapi, bukan Firaun sendiri yang menghadapi Musa melainkan tukang sihir bayaran. Musa mengecam sikap pengecut Firaun ini. ${ }^{36}$ Firaun membela diri dan kembali menuding Musa benar-

31 Q.S al-Syuara 26: 18-22

32 Q.S al-Syuara 26: 25

${ }^{33}$ Q.S al-Qashash 28: 38. Lihat juga Q.S al-Mukmin 40:36-37. Firaun mengeluarkan perintah sindiran kepada Haman agar membuat bangunan yang tinggi menjulang ke pintu-pintu langit sehingga Firaun dapat melihat Tuhan Musa. Firaun memandang Musa tak ubahnya pendusta.

${ }^{34}$ Q.S al-Syuara' 26:27-28

${ }^{35}$ Q.S Thaha 20:57-59

${ }^{36}$ Q.S Thaha 20:61 
benar akan mengkudeta dirinya.37 Firaun menjanjikan hadiah istimewa bagi ahli sihir-ahli sihirnya bila dapat mengalahkan Musa. ${ }^{38}$

Musa menantang ahli-ahli sihir Firaun sekaligus. Para tukang sihir itu mendemonstrasikan kekuatannya berupa tali-tali dan tongkat yang dilemparkan menjadi binatang yang merayap dengan cepat ke arah Musa. Demo itu membuat Musa gentar. Allah menguatkannya untuk maju. Dengan gegas Musa melempar tongkatnya menjadi ular besar yang melahap binatang-binatag sihir itu. Tak ayal, tukangtukang sihir Firaun terperangah dan mengaku takluk kepada Musa. Mereka menyatakan beriman kepada Allah. ${ }^{39}$

Firaun geram dengan tindakan tukang sihirnya. Ia mengancam mereka dengan potong tangan dan salib di pangkal pohon kurma (Q.S Thaha 20:71). Firaun mengumbar serapahnya bahwa siksanya lebih pedih dari siksa yang diancamkan Musa. Ternyata para tukang sihir itu mantap dengan pilihan keyakinannya karena meyakini buktibukti yang ditunjukkan Musa.

Sepak terjang Musa yang fenomenal membuat cemas pejabatpejabat Firaun. Mereka mengagitasi Firaun agar mengambil langkah untuk menjaga wibawa Firaun. Firaun menurunkan perintah untuk membunuh semua anak laki-laki keturunan bani Israel. Perintah "pembersihan" ini merupakan bentuk kegeraman Firaun karena pernah mengasuh Musa saat bayi dan kini menentangnya. ${ }^{40}$ Mengamati ancaman yang mengincar diri dan kaumnya, Musa menguatkan mental kaumnya. Tetapi, bani Israel di Mesir justru berpandangan kedatangan Musa memperburuk keadaan. Musa tidak menyerah untuk menyemangati kaumnya. ${ }^{41}$

Azab Allah kepada Firaun mulai diturunkan. Kemarau panjang membuat Mesir kekurangan pangan. Azab ini justru memberikan kesempatan kepada Firaun dan orang-orang di Mesir untuk

37Thaha 20:63. Sebenarnya diam-diam ada pejabat Firaun yang mempercayai Musa dan ajaran-ajarannya. Ia berusaha dengan halus mengubah kebijakan keras Firaun kepada Musa (al-Mukmin 40:28).

38 As-Syuara 26:41-42

${ }^{39}$ Thaha 20:67 dan Al-A'raf 7:115-120

40 al-A'raf 7:127, Ibrahim 14: 6, dan al-Mukmin 40: 25

${ }^{41}$ Al-A'raf 7:129. Meskipun sebenarnya, hanya para pemuda bani Israel yang mempercayai perjuangan Musa membebaskan kaum bani Israel dari tindakan aniaya Firaun (Yunus 10:83). 
mempersalahkan Musa. Hingga azab berikutnya diturunkan berupa topan, belalang, kutu, katak dan darah. Rupanya bencana ini membawa perubahan sikap. Orang-orang kafir Mesir minta kepada Musa untuk dimohonkan kepada Allah agar bencana itu hilang. Setelah itu mereka akan mematuhi Musa. Tetapi, ketika bencana azab itu dihilangkan, mereka ingkar janji. ${ }^{42}$

\section{Misi Pembebasan Bani Israel dari Cengkeraman Firauan (PL)}

Musa dan Harun menjumpai firaun dan memohon kepada penguasa Mesir itu untuk mengizinkan orang-orang Israel pergi beribadah di tengah gurun yang jarak tempuhnya tiga hari dalam rangka berkurban kepada Allah. Firaun tidak memenuhi permintaan itu. Ia mencemooh siapakah Allah yang harus didengarnya itu sehingga ia harus melepaskan bani Israel. Firaun tersinggung dengan tindakan Musa. Ia langsung memerintahkan pencabutan penyediaan jerami sebagai bahan bakar pembuat bata kepada orang-orang bani Israel tetapi meminta agar mereka tetap memenuhi target batu bata yang harus dibuat seperti ketika bani Israel dibantu pasokan jerami sebelumnya. Akibatnya, Musa dipersalahkan oleh kaumnya. Ia dinilai tidak membantu apapun bahkan menambahkan beban berat. ${ }^{43}$ Musa mengeluh kepada Allah karena bani Israel tidak menaruh kepercayaan kepadanya. ${ }^{44}$

Tidak ada jalan lain bagi Musa. Ia harus meyakinkan firaun sebagai utusan Tuhan yang sebenarnya. Mukjizat Tuhan ditunjukkan kepada firaun berupa tongkat ajaib menjelma ular dan melahap ularular ahli sihir firaun. ${ }^{45}$ Tetapi ini tidak cukup karena firaun keras kepala. Silih berganti mukjizat berupa bencana diturunkan seperti tongkat ajaib merubah semua sumber air di Mesir menjadi darah, ${ }^{46}$ semua sumber air dipenuhi katak, debu menjadi nyamuk yang memenuhi seluruh wilayah Mesir, ${ }^{47}$ sampar, barah, hujan es, guruh dan kilat api, hingga serbuan belalang yang memekat di seluruh dataran Mesir menghabiskan tidak saja tanaman tetapi juga

\footnotetext{
${ }^{42}$ Al-A'raf 7:130-133

${ }^{43}$ Kel. 5:1-23

${ }^{44}$ Kel. 6:12

${ }^{45}$ Kel. 7:10

${ }^{46}$ Kel.7:19

${ }^{47}$ Kel. 8:6 dan 8:17
} 
pepohonan. ${ }^{48}$ Namun firaun tidak juga bergeming untuk mengekang bani Israel. Sesekali saja, ketika bencana-bencana itu berkepanjangan, ia mengijinkan Musa dan bani Israel keluar untuk beribadah. Begitu bencana usai, firaun kembali menindas bani Israel.

\section{Eksodus dari Mesir (al-Quran)}

Firaun tidak jenak dengan Musa. Ia berencana mencelakai Musa dan mengusir orang-orang bani Israel. Ia menyampaikan rencananya itu kepada para pembesarnya. Firaun tidak mau dirinya dipecundangi oleh bani Israel. Firaun bersiap-siap dengan mengumpulkan tentara-tentara terbaiknya untuk menumpas Musa dan bani Israel. ${ }^{49}$

Allah memerintahkan Musa dan bani Israel untuk pergi keluar dari Memphis pada malam hari. Mendengar Musa meninggalkan kota pada malam hari, Firaun dan pasukannya bergerak untuk menyusul mereka. Rombongan Musa dapat disusul pasukan Firaun ketika matahari mulai terbit di sebuah pinggiran sungai Nil. Nabi Musa menenangkan kaumnya. ${ }^{50}$

Nabi Musa diperintah Allah memukulkan tongkatnya ke arah lautan. Seketika lautan menjadi terbelah dua membentuk jalur menyeberang. Air di kedua sisi belahan itu seperti gunung yang besar. Dalam rasa takjub, rombongan Nabi Musa melewati belahan itu dengan cepat hingga ke seberang. Sedangkan Firaun dan tentaranya berusaha menyusul masuk ke dalamnya. Akan tetapi, Firaun dan tentaranya ditenggelamkan oleh Allah. Keberadaan bani Israel di Mesir sejak masa Nabi Yusuf, berakhir di masa Nabi Musa. ${ }^{51}$

\section{Eksodus yang Sarat Polemik (PL)}

Kebebalan Firaun mulai diakhiri dan Tuhan menjanjikan kemurahan hati bagi bani Israel. Semua anak sulung orang-orang

\footnotetext{
${ }^{48}$ Kitab Keluaran 9 dan 10 menjelaskan hal ini

${ }^{49}$ Q.S al-Mukmin 40:26; Q.S al-Syuara 26:53-54. Lihat juga Q.S al-Isra' 17:103

${ }^{50}$ Q.S al-Syuara 26:60-62

${ }^{51}$ Q.S al-Syuara 26:66 dan Thaha 20:78. Dalam al-Hajj 22:44, al-Mukminun 23:45-48, dan al-Furqan 25:35 diterangkan juga potongan kisah Musa Misal, tentang azab atas orang yang mendustakan ajaran Musa, kedatangan Musa dan Harun dengan membawa tanda-tanda kebesaran Allah, anugerah Taurat, dan sikap congkak Firaun yang berujung azab.
} 
Mesir termasuk anak-anak sulung binatang di Mesir mati mendadak. Orang-orang Mesir panik. Mereka memenuhi apapun yang diinginkan orang-orang Israel (termasuk emas, perak, kambing, sapi dan kain) jika bani Israel segera meninggalkan Mesir. Kurang lebih enam ratus ribu orang bani Israel meninggalkan Mesir dengan cukup bekal. Firaun sendiri tidak tahu mengenai hal ini. Berakhirlah keberadaan bani Israel di Mesir selama 430 tahun. Dituturkan bahwa Musa meninggalkan negeri itu dengan amarah yang berkobar. 52

Allah tidak mengarahkan bani Israel ke arah Palestina yang jaraknya lebih dekat. Sebab, bani Israel tidak siap menghadapi resiko dan lemah mental. Mereka dituntun memutar di padang gurun menuju laut Teberau. ${ }^{53}$ Begitu laporan diketahui bani Israel telah meninggalkan Mesir, Firaun menyesal melepaskan Musa dan bani Israel begitu saja. Firaun dan tentaranya mengejar bani Israel. Dan hampir saja dapat menyusul rombongan besar bani Israel yang ketakutan. Namun, Musa berhasil menyelamatkan kaumnya dari kejaran firaun dengan mukjizat tongkat yang membelah laut sehingga bani Israel selamat dan firaun tenggelam. ${ }^{54}$

Setelah berhasil keluar Mesir, bani Israel melewati padang gurun Syria selama tiga hari. Bani Israel kecapaian karena haus. Mereka merajuk dan menyalahkan Musa atas penderitaan itu. Bani Israel memelihara sikap rendah ini hingga Musa mangkat. Dengan pertolongan Allah, Musa menunjukkan mukjizatnya dengan menancapkan kayu ke tanah dan memancarkan sumber mata air sebanyak kabilah bani Israel yaitu 12 sumber mata air. Selain itu, tumbuh juga 70 pohon kurma. ${ }^{55}$ Tidak cukup protes karena kehausan, tetapi juga kelaparan. Bantuan datang dari Allah berupa roti.

\section{Momen Sinai Kedua (al-Quran)}

Nabi Musa memiliki semacam kewajiban bila selamat dari incaran kejaran firaun untuk bermunajat di sisi kanan gunung Sinai. Musa menyerahkan urusan umat kepada Harun selama Musa

52 Kitab Keluaran 11 mengilustrasikannya dengan lengkap. Dalam al-Quran, justru firaunlah yang bersungut-sungut atas sepak terjak Musa sehingga ia menyusun rencana untuk membunuh Musa dan mengusir bani Israel dari tanah Mesir.

${ }^{53}$ Kel. 13:17-18

${ }^{54}$ Kel. 14:5-30

55 Kel. 15:27 
munajat ke Thur Sinai. Sesampainya di Thur Sinai untuk munajat kepada Allah dan menerima Taurat, Musa memohon agar Allah berkenan menampakkan diri-Nya.

Momen pertemuan pertama dengan Allah, Musa hanya berkomunikasi dengan suara. Pada momen pertemuan kedua ini, Musa tidak dapat menahan rasa penasaran untuk melihat Allah. Tetapi rupanya Musa tak sanggup bertahan dalam kesadarannya dan pingsan ketika dia diuji coba untuk melihat sebuah gunung sebagai wadah penampakan Allah. Musa menyadari kapasitas kemanusiaanya tidak akan mampu menjangkau dzat Allah. Musa hanya mampu beraudiensi "via phone" dengan Allah. Dan saat itu Musa menerima Taurat yang telah ditulis dalam lembaran-lembaran batu atau kayu. ${ }^{56}$

Di saat kepergian Musa ke Thur Sinai, bani Israel diuji oleh Allah. ${ }^{57}$ Mereka disesatkan oleh Samiri, seorang bani Israil dari suku Assamirah. Tokoh dengan nama Samiri belum disebutkan dalam Q.S al-A'raf 7:148. Tetapi dalam Q.S Thaha 20:85, nama Samiri disebutkan dengan jelas sebagai aktor dibalik penghianatan akidah. Musa pun kembali ke kaumnya dengan sedih dan marah. Ia menumpahkan kekesalannya pada kaumnya (Q.S al-A'raf 7: 150-154). Begitu kecewanya, hingga Musa melempar lembaran Taurat. Bani Israel berdalih terbebani membawa emas yang dibawa dari Mesir. Oleh karenta itu ketika Samiri meminta mereka melempar emas-emas itu ke dalam api, mereka memenuhinya. Samiri menyepuhnya menjadi patung anak lembu. Mereka terkesima dengan patung itu dan berguman bahwa patung itu adalah tuhan mereka dan tuhan Musa (patung anak lembu itu itu merupakan tiruan berhala orang-orang Mesir: Hathor dan Aphis. Orang-orang bani Israel akrab dengan tradisi pagan Mesir). Sebenarnya Harun telah mencoba mengingatkan mereka. Tetapi mereka tetap menyembah patung anak lembu itu hingga Musa kembali dari munajat. 58

Musa juga menumpahkan kekesalannya pada Harun Ia kecewa kepada Harun yang dianggap tidak mampu mengemban amanat

${ }^{56}$ Q.S Thaha 20:80-83 dan Q.S al-A'raf 7: 143-145

${ }^{57}$ Q.S al-Shaff ayat 5 turut menceritakan penghianatan kaum Musa atas ajaran-ajaran Nabi Musa.

58 Q.S Thaha 20:88 
yang dititipkan kepadanya ketika ia akan pergi ke Thur Sinai. Begitu juga Samiri, tidak luput dari amarah Nabi Musa. Samiri mengakui kekhilafannya sebagai orang yang memiliki kemampuan supranatural tetapi disalahgunakan. Musa menghukum Samiri dengan mengusirnya dari komunitas bani Israel. Sedangkan patung anak lembu yang disepuh Samiri, dihancurkan. ${ }^{59}$

Kemarahan Musa mereda setelah ia memohon ampun atas dirinya dan saudaranya, Harun serta mengutuk aksi-aksi paganisme kaumnya. Musa memunguti kembali lembaran-lembaran Taurat yang dilemparnya karena perasaan emosional itu. Musa memilih 70 orang dari kaumnya untuk bertobat kepada Allah. Gempa mengoncang daerah yang dihuni kaum Nabi Musa. Nabi Musa panik. Ia mohon ampun kepadaNya untuk tidak mengazab kaumnya hanya karena ulah beberapa oknum kaumnya yang kurang akal sehingga menyeleweng. ${ }^{60}$ Pada peristiwa ini, terdapat keterkaitan dengan kisah Karun yang ambles ke bumi karena ketamakan dan kesombongannya.

Setelah berlalu, Musa meminta kepada kaumnya untuk menyembelih sapi betina. Hikmah dari Allah menyuruh menyembelih sapi supaya hilang rasa penghormatan mereka terhadap sapi yang pernah mereka sembah. Setelah didesak, kaum Musa menuruti perintahnya untuk menyembelih sapi betina dengan ciri : tidak terlalu tua dan tidak terlalu muda, berwarna kuning tua yang elok, belum pernah dimanfaatkan untuk membajak atau mengairi, tidak cacat, dan tidak belang. Hampir saja perintah itu diabaikan karena sulitnya mencari sapi betina dengan ciri-ciri tersebut. ${ }^{61}$

Perjalanan ke luar negeri Mesir bukanlah tanpa tujuan. Nabi Musa dan kaumnya hendak menuju tanah suci yang telah ditentukan

${ }^{59}$ Q.S al-A'raf 7:150 dan Q.S Thaha 20:93-97

60 Q.S al-A'raf 7:151-155

61 Sulitnya syarat tersebut akibat kerewelan bani Israel sendiri. QS Al-A'raf 7:67 dan al-Baqarah 2:67-73. Beberapa mufassirin berbeda-beda menjelaskan mengenai kisah sapi betina ini. Salah satunya adalah sapi betina ini bagian dari diyat pembunuhan atas seorang konglomerat Israel (mungkin saja kolega Karun, peny) oleh keponakannya miskin yang ditolak menikah dengan putri sang konglomerat. Tersangka pembunuhan sebenarnya bukan pemuda itu tetapi orang lain yang menemukan mayat si konglomerat. Dengan cerdik si keponakan menjebak orangorang yang menemukan mayat pamannya dan menuntut mereka. Muhammad Qutb, al-Qishshah fi al-Quran..., 350-351 
oleh Allah bagi mereka. Namun, kaum Nabi Musa adalah kaum pesimistis, tidak teguh pendirian, dan pembohong. ${ }^{62}$ Menjelang akhir perjalanan masuk menguasai Palestina pun, orang-orang Israel masih merepotkan Nabi Musa. Orang-orang Israel bersikap pengecut saat mengetahui lawan kuat di kota Palestina. Bahkan mereka tidak punya kesetiaan apapun kepada Nabi Musa yang begitu bersemangat hendak masuk menyerbu dan menguasai Palestina. ${ }^{63}$ Akibatnya, Allah benar-benar membuat orang-orang itu menggelandang di padang Tih (utara Sinai) selama empat puluh tahun. ${ }^{64}$

Sebenarnya tidak semua kaum Nabi Musa menyeleweng. Di antara mereka ada orang-orang yang mengikuti petunjuk Nabi Musa dan memberi petunjuk sebagaimana petunjuk Nabi Musa. Misal, tetangga-tetangga Karun yang mengingatkan Karun agar tidak dibuai urusan keduniaan. Allah mengasihi Nabi Musa65 dan umatnya.

${ }^{62}$ Moral dan mental buruk bani Israel juga dijelaskan dalam Q.S al-Baqarah 2:99-101 dan Q.S Ali Imron 3:75-78

63 Ketakutan menimpa bani Israel saat Allah memerintahkan Musa bersiap memasuki Palestina. Mereka merasa bukan ahli bertempur melawan kelompok al-Jababirah yang menguasai Palestina. Larangan masuk ke Palestina selama 40 tahun, menurut Ibn Khaldun, menyimpan rahasia. Masa selama itu adalah masa pergantian generasi baru bani Israel yang lebih baik; yang lebih siap memasuki dan menjaga Palestina. Attihami Naqrah, Sikulujiyat al-Qishshah fi al-Quran, (Seri Desertasi : Universtas alJazair, 1971), 200-201

${ }^{64}$ Q.S al-Maidah 5:21-25. Nabi Musa hingga akhir hayatnya juga tidak dapat memasuki Palestina karena ulah kaumnya itu. Orang-orang Israel baru dapat memasuki Palestina pada masa Yusa' bin Nun, cantrik Nabi Musa yang meneruskan perjuangan Nabi Musa dan Nabi Harun. Sejak tenggelamnya firaun, Allah tidak lagi menerapkan bencana "tebang pilih". Allah menerapkan "sistem" bencana model "sapu bersih", yaitu bencana yang tidak pandang bulu memakan korban apakah orang saleh atau bukan. Orang yang saleh harus berjuang sendiri habis-habisan mengoreksi umatnya agar tidak diazab oleh Allah. Jika tidak, ia pun akan dapat menjadi korban azab Allah atas umatnya itu. Kenyataan ini berbeda dengan sebelum firaun binasa di laut. Allah hanya menggasak para pembangkang saja, seperti umat pembangkang Nabi Nuh dengan banjir, kaum pembangkang Nabi Saleh dilahap bumi, dan kaum penentang Nabi Luth dihujani batu. Tetapi orang-orang saleh kaum-kaum itu dijauhkan dari marabahaya azab oleh Allah. Yahya C. Staquf, Catatan atas Catatan, Kompas/2/1/08

65 Ada riwayat yang kontroversial yang mengisahkan tentang cara meninggal Nabi Musa. Riwayat ini disandarkan kepada Rasulullah dengan mata rantai sanad Abu Karib dari Mas'ab bin al-Maqdam dari Hammad bin Salamah dari 'Ammar bin Abi Ammar, budak bani Hasyim dari Abu Hurayrah. Nabi diriwayatkan bersabda bahwa dulu malaikat maut mencabut nyawa manusia dengan alat penglihatan. Akan tetapi, 
Hanya terkadang mereka sendiri yang berlaku aniaya terhadap diri mereka sendiri.

\section{SINAI KEDUA (PL)}

Ketika perjalanan mereka sampai di dekat padang Sinai66 (di Rafidim), untuk pertama kalinya orang-orang Israel harus bertempur dengan suku Amalek. Bani Israel yang dipimpin Yoshua berhasil menang melalui kekuatan mukjizat tongkat Musa. Harun dan Hur turut mendampingi Musa naik ke puncak bukit untuk menyalurkan energi gaib tongkat itu. ${ }^{67}$ Setelah pertempuran di Rafidim itu, bani Israel meneruskan perjalanan hingga padang gurun Sinai. Mereka semua berhenti karena Musa harus menghadap Allah untuk menerima hukum berupa sepuluh perintah Tuhan (kitab Keluaran 20). Yang diperbolehkan naik ke Sinai menemui Allah hanya Musa dan Harun. ${ }^{68}$ Pertemuan kedua Musa dengan Allah di Sinai terjadi pada bulan ketiga setelah mereka keluar dari Mesir. ${ }^{69}$

Bani Israel menunggu kedatangan Musa dari puncak Sinai. Mereka menunggu hal apa yang akan disampaikan Musa kepada mereka. Selang beberapa waktu, mereka sudah tidak sabar dan menduga Musa sengaja berlama-lama di Sinai. Menariknya, Harun

ketika malaikat maut mendatangi Musa untuk mencabut nyawanya, Musa menampar malaikat itu dan mencongkel matanya. Malaikat maut melapor kepada Allah atas kejadian itu dengan berang. Menurutnya andai saja Allah tidak memuliakan Nabi Musa, pastilah ia akan mencincang Nabi Musa. Perintah "tangkap" paksa pun turun dari Allah agar malaikat maut mengunci telapak tangan Musa di atas punggung sapi jantan. Kemudian Musa ditawari dua opsi : tangannya akan ditumbuhi bulu-bulu yang lebat selamat setahun atau nyawanya bersedia dicabut saat itu juga oleh malaikat maut. Musa ternyata memilih dicabut nyawanya. Karena sudah tidak bisa melihat, malaikat maut mengandalkan indera penciumannya untuk mencabut nyawa Nabi Musa. Setelah peristiwa itu, malaikat maut datang menjemput ajal manusia secara diam-diam. Lihat Abu Ja'far Muhammad bin Jarir al-Thabari, Tārìkh al-Thabari: Tārìkh al-Rusul wa al-Muluk, Jilid 1, Cet. II, (Dar al-Ma'arif: Mesir, tth), 375

66 Berdasarkan Kel. 16:1 dan 17:6, Horeb adalah nama tempat yang sama dengan Sinai ${ }^{67}$ Kel. 17:8-13

${ }^{68}$ Kel. 19:24. Keterangan ini tidak konsisten bila dikonfirmasi dengan keterangan yang lain yang menyatakan bahwa Harun tidak turut-serta melainkan diserahi urusan umat selama Musa naik ke Sinai. Selama Musa naik ke puncak Sinai, ia menyerahkan urusan umat kepada Harun dan Hur. (Kel. 24:14)

69 Kel. 19:1 
dituturkan menjadi bagian dari situasi itu bahkan ia memimpin orang-orang Israel membuat patung anak lembu dari anting-anting emas pemberian orang Mesir. Orang Israel kemudian mendeklarasikan anak lembu itu adalah "Allah" yang menuntun mereka keluar dari tanah Mesir. ${ }^{70}$ Musa diperintahkan oleh Allah untuk segera turun mengendalikan suasana. Ia tidak dapat menutupi rasa kecewanya kepada Harun dan kaum bani Israel. Ia membanting lembaran batu perintah Allah hingga pecah. Mereka diazab dengan korban tiga ribu nyawa mereka dan anak-anak mereka. ${ }^{71}$

\section{Kisah Karun (al-Quran)}

Kisah Karun merupakan fragmen riwayat Nabi Musa yang cukup terkenal dalam Islam. Karun ${ }^{72}$ adalah kaum Nabi Musa yang sangat kaya-raya. Al-Quran menggambarkan kekayaan Karun yang luar biasa dengan: Peti harta yang kunci-kuncinya saja sangat berat untuk dipikul oleh beberapa orang yang kuat sekalipun. Karun adalah sosok antagonis yang sombong karena harta. Ia diingatkan oleh temantemannya agar tidak egois, narsis dan tidak melupakan akhirat.

Alih-alih mendengarkan anjuran tetangganya, Karun malah bersikap sombong dan tidak terkendali. Ia giat memamerkan kekayaan sehingga menimbulkan kecemburuan dan utopia social. Tetapi warga bani Israel yang imannya teguh menyangkal mimpimimpi saudaranya yang tergiur gemerlap kekayaan Harun agar hanya berharap pahala dari Allah. ${ }^{73}$

Tetapi tidak lama, gempa melanda (gempa ini dapat diduga berkaitan juga dengan azab Allah kepada bani Israel yang menyeleweng dari ajaran Musa ketika mereka ditinggal Musa bermunajat ke Thur Sinai. Ini logis mengingat tidak nampaknya peran Musa dalam kisah Karun ini. Jadi, kisah Karun ini terjadi dalam kurun waktu Nabi Musa menerima Taurat di Sinai). Karun dan hartanya, amblas ke dalam perut bumi tanpa sisa. Orang-orang bani

\footnotetext{
${ }^{70}$ Kel. 32:1-5

71 Kel. 32:27-29

72Q.S al-Qashash 28:76-77. Ada yang berpendapat bahwa Qarun adalah sepupu Nabi Musa dari pihak ayah (Imran bin Humair) dan ada yang menyatakan ia adalah paman Nabi Musa. Di dalam Taurat ia digambarkan sebagai orang yang rupawan. Lihat Abu Ja'far Muhammad bin Jarir al-Thabari, Tārikh al-Thabari..., 365

${ }^{73}$ Q.S al-Qashash 28:78-80
} 
Israel pengagum Karun terhenyak dan bersyukur tidak bernasib seperti Karun. ${ }^{74}$

\section{Kisah Karun (Korah) (PL)}

Korah adalah anak Yizhar paman Nabi Musa. Ia memimpin 250 orang wakil bani Israel untuk menyampaikan mosi tidak percaya kepada Musa terkait otoritasnya. Mereka meminta Musa menerapkan prinsip egaliter karena menganggap diri mereka juga suci sepertihalnya Musa dan Harun. ${ }^{75}$ Alasan lain menentang Musa adalah anggapan bahwa Musa gagal membawa bani Israel ke negeri yang berlimpah susu dan madu. ${ }^{76}$ Orang-orang Israel selalu menyalahkan Musa ketika mereka terhimpit kesulitan dan selalu mendengungdengungkan penyesalan keluar dari negeri Mesir menuju kesengsaraan dan kematian. ${ }^{77}$

Korah, harta benda, dan pendukungnya pun ditimpa bencana ditelan bumi tanpa sisa (Bil. 16:32). Hal ini mengenaskan mengingat Tuhan berjanji kepada Musa dan Harun, tidak akan menghukum bani Israel yang menyingkir jauh dari rumah Korah. Tetapi ternyata Tuhan mengadzab semua orang yang bekerjasama dengan Korah menentang Musa. Termasuk di dalamnya keluarga (istri dan anak-anak) Datan dan Abiram (dua tokoh pembangkang bersama Korah). ${ }^{78}$ Murka Tuhan berlanjut di hari berikutnya, ketika bani Israel menuduh Musa sebagai "pembunuh umat-Nya" dalam tragedi Korah. Murka Tuhan berkobar sehingga empat belas ribu tujuh ratus orang bani Israel nyawanya melayang. ${ }^{79}$

\footnotetext{
74 Al-Qashash 28:81. Firaun dan anteknya Haman serta kaum Nabi Musa, Karun adalah nama-nama yang disiksa dengan berbagai jenis siksaan : ditenggalamkan dan dibenamkan ke dalam perut bumi. Itu semua akibat perbuatan mereka sendiri yang sombong. Allah sama sekali tidak berbuat aniaya terhadap mereka. Akan tetapi, merekalah yang menganiaya mereka sendiri (Q.S al-Ankabut 29:39-40)

75 Bilangan 16:1-3

76 Bilangan 16:13-14

77Terhitung 6 peristiwa terpisah yang ditulis dalam Alkitab saat Israel mengeluh terhadapnya. Richard L. Strauss, Hal Terpenting, dalam

http://www.bible.org/page.php?page_id=3728 yang direkam pada 15 Des 2007 05:26:19 GMT

78 Bilangan 16:24-35

79 Bilangan 16:49
} 
Sosok Yoshua bin Nun adalah abdi perjuangan Moses (Musa). ${ }^{80}$ Yoshua dan Caleb bin Yefnua memimpin bani Israel sepeninggal Moses untuk memasuki Yerussalem (Yoshua :1-5) yang gagal dilakukan semasa Moses. ${ }^{81}$ Setelah memimpin selama empat puluh tahun, dan menjelang saat memasuki Tanah Perjanjian terjadilah proses alih generasi kepemimpinan. Musa diganti oleh Yoshua bin Nun. Sewaktu Musa meninggal dia berusia seratus duapuluh (120) tahun, dan "matanya belum kabur dan kekuatannya masih belum hilang." (Ul. 34:7). Ternyata untuk memasuki Tanah Perjanjian, Tuhan memerlukan dan menghendaki jenis dan kualitas kepemimpinan lain (job requirements). Menurut hasil pernilaian Tuhan (fit $\mathcal{E}$ proper test), Yosua bin Nun diberikan yudisium: "Seorang yang penuh roh" (Bil. 27:18-23). ${ }^{82}$

\section{Momen yang Tidak Dikisahkan dalam al-Quran: Sinai Ketiga (PL)}

Setelah tragedi heterodoksi akidah saat Musa naik ke Sinai pada momen kedua, Musa naik lagi ke Sinai untuk menulis kembali perintah-perintah Allah dalam lembaran batu yang sebelumnya rusak ketika dirinya lepas kendali akibat ulah Harun dan bani Israel. ${ }^{83}$ Musa ada di puncak Sinai selama empat puluh hari dan malam, tanpa bekal konsumsi. Ia menulis kembali The Ten Commandments sebagai kitab perjanjian antara Tuhan dan bani Israel. Yang tak disangka Musa, sehabis dari Sinai, wajah Musa bercahaya karena ia telah berbicara dengan Tuhan. Setelah itu Musa selalu menyelubungi mukanya kecuali untuk berbicara di depan umatnya 84

Peperangan di Rafidim di waktu terdahulu, berlanjut dengan pertempuran di seberang sungai Yordan melawan dua penguasa daerah. Bani Israel memang diperintahkan merebut dan menguasai daerah yang mereka lewati seperti Nejed, Yordan, Lebanon, dan

\footnotetext{
${ }^{80}$ Ulangan: 34/Yoshua:1

${ }^{81}$ http://www.bible.org/page.php?page_id=3672 yang direkam pada 15 Des 2007 05:48:04 GMT.

82 http://www.gkipi.org/files/bible_tks/041209.htm yang direkam pada 8 Des 2007 18:48:13 GMT.

83 Kel. 34:1-5

84 Bilangan 34:29-33
} 
Efrat. Tanah-tanah itu telah dijanjikan (dengan sumpah) Allah kepada moyang bani Israel (Ibrahim, Ishak, dan Ya'qub) dan keturunannya. 85

\section{Momen yang Tidak Dikisahkan dalam Perjanjian Lama: Berguru kepada Khidir ${ }^{86}$}

Inilah kisah perjalanan Musa dan muridnya, bernama Yusya' bin Nun, untuk berguru kepada Khidir. Sebenarnya nama Khidir tidak termaktub dengan jelas. Al-Quran hanya menyebutnya sebagai hamba yang dirahmati dan diberkati pengetahuan ('abdan min 'ibädina atainahu rohmatan min 'indina wa 'allamnahu min ladunna 'ilma). ${ }^{87}$ Musa dan muridnya sempat terlewat dari tempat dimana ikan yang mereka bawa meloncat dan kembali ke lautan. Padahal di sana mereka dapat bertemu Khidir. Yusa' lupa mengatakan kepada Musa ketika ikan itu betul-betul melompat di suatu tempat. Mereka pun kembali lagi mengikuti jejak semula hingga sampai ke tempat dimana ikan itu jatuh, yaitu sebuah tempat bertemunya dua buah lautan. ${ }^{88}$ Keduanya pun bertemu Khidir.

Musa mohon kepada Khidir agar diperkenankan belajar ilmu kebenaran. ${ }^{89}$ Khidir menjawab pesimis sanggup bersabar bersama

\footnotetext{
85 Ulangan 1:4-8

${ }^{86}$ Q.S al-Kahfi 18:60-77. Berdasarkan riwayat dari Basyar bin Muadz dari Yazid dari Syu'bah dari Qatadah dikisahkan bahwa misi Musa menemui Khidir karena klaim Musa setelah selamat dari kejaran Firaun di laut Merah. Musa menyatakan bahwa bani Israel adalah komunitas terbaik dan paling cerdik di muka bumi. Tetapi kemudian dikabarkan kepada Musa bahwa hal itu tidak sepenuhnya benar karena nun jauh di sana ada seorang yang lebih cerdik dari Musa. Mendengar hal itu, Musa berangkat bersama cantriknya, Yusa' bin Nun (bin Afrayim bin Yusuf bin Ya'qub bin Ishaq bin Ibrahim, calon Nabi suksesor Musa berikutnya) untuk mencari Khidir. Bernama Khidir karena konon ia berwarna kulit hijau akibat duduk di atas wadah dari kulit yang putih. Wadah itu menggoyang-goyang hingga dirinya menjadi hijau. Siapakah Nabi Khidir sebenarnya? Ada banyak riwayat mengenai sosoknya yang misterius tersebut. Lihat Abu Ja'far Muhammad bin Jarir al-Thabari, Tārikh alThabari..., 365-371 dan Abu al-Faraj Abdurrahman bin Ali bin Muhammad bin Ibn alJauzi, al-Muntadzam fi Tārīkh al-Muluk wa al-Umam..., 358

87 Al-Kahfi 18:65

88 Ada dua pendapat mengenai tempatnya, yaitu di laut Merah di sisi kiri-kanan dataran Sinai dan selat Jabal Thariq (Gibraltar) yang memisahkan Marokko dan Spanyol. Lihat Syauqi Abu Khalil, Athlas al-Quran..., 83

${ }^{89}$ Kisah dialogis Musa dan Khidir terekam dalam QS al-Kahfi 18:66-82
} 
Syukron Affani

Nabi Khidir terutama atas hal-hal yang jauh dari pemahaman Musa. Tetap Nabi Musa bersikeras.

Musa diijinkan mengikuti Khidir. Beberapa peristiwa terjadi. Tetapi Musa tidak dapat menahan diri atas tindakan-tindakan Khidir yang dinilai berlebihan. Akhirnya Khidhr mengambil kesimpulan atas sikap Musa yang selalu tidak mempercayai apapun yang diperbuatnya. Khidir memandang Musa tidak cocok berguru kepadanya. Musa memahami keputusan Khidir. Setelah itu, Musa terdiam mendengar semua penjelasan Khidir. Musa yang merasa dirinya dan kaumnya sebagai umat terbaik dan tercerdik, tidak dapat menggapai pengetahuan batin Khidir yang meta-rasional. Khidir menutup perjumpaannya dengan Musa.

\section{Beberapa Perbedaan dan Persamaan}

Perbedaan antara al-Quran dan Perjanjian Lama (PL/The Old Testament) dalam mengisahkan Musa dan Harun, terjadi dalam banyak hal. Misal (untuk menyebut beberapa contoh):

Pertama, dalam al-Quran digambarkan ketidaksengajaan dan penyesalan Nabi Musa karena terlibat dalam pembunuhan laki-laki Qibti. Namun dalam PL, dikesankan Nabi Musa terlibat aktif dalam kasus tersebut. Kedua, tokoh Samiri dalam al-Quran tidak ada dalam Perjanjian Lama (PL). Peran Samiri itu dalam PL, diisi oleh Harun. Ketiga, momen pertama Thur Sinai dalam al-Quran terjadi ketika Musa dan keluarganya akan menjenguk ke Mesir. Dalam PL, terjadi ketika Musa menggembalakan kambingnya. Keempat, peran Harun tidaklah menonjol dalam al-Quran. Namun, dalam PL asistensi Harun menonjol sebagai juru bicara Musa bahkan juru operasional mukjizat. ${ }^{90}$ Misal, ketika melawan ahli-ahli sihir firaun. Dalam PL, Harun bukan tokoh pelengkap seperti dalam al-Quran melainkan tokoh pemeran pembantu yang signifikan. Kelima, Karun diazab oleh Allah karena sikap pongah dan kegandrungannya pada harta yang melewati batas. Demikian al-Quran memaparkannya. Hal itu sama sekali berbeda dengan ungkapan PL. Karun (Korah) dilahap bumi karena melakukan upaya "coup d 'etat" terhadap kepemimpinan Nabi Musa. Al-Quran menjelaskan berdasarkan motif ekonomis-teologis. PL mengungkapkan berdasarkan faktor politis-teologis. Keenam, tidak

${ }^{90}$ Lihat Kel. 4:30-31; 7:10; 17:19; 8:6; 8:17 
ada jejak figur Khidir atau yang menyerupainya dalam PL. Al-Quran sendiri memang tidak eksplisit menyebutkan Khidir. ${ }^{91}$ Ketujuh, misi Musa dalam PL adalah bani Israel. Dalam al-Quran, misi Musa, disamping menyelamatkan bani Israel, juga untuk menggugah firaun bertauhid. ${ }^{92}$ Namun, narasi al-Quran mengenai perjuangan Musa di Mesir jauh esensial dari narasi Bibel. Dalam al-Quran, kesejarahan firaun yang congkak hingga menganggap dirinya yang agung dan mendaku sebagai tuhan, harus dihentikan. ${ }^{93}$ Hal ini tidak untuk menunjukkan bahwa Allah merasa disaingi, melainkan lebih pada dampak yang ditimbulkan akibat sikap itu. Yaitu, sikapnya yang despotik dan tiranik terhadap rakyat terutama orang-orang Israel.

\footnotetext{
91 Alpanya kisah Nabi Musa bersama Khidir dalam literatur Yahudi ini mengejutkan beberapa ahli cerita Israiliyat seperti seorang laki-laki yang bernama Nuf dari Kufah. Ia menilai, Musa dalam kaitannya dengan Nabi Khidir ini bukanlah Musa Nabi Bani Israel tetapi Musa teman Nabi Khidir yang benama Musa bin Misya. Ibn Abbas membantah anggapan Nuf tersebut dan menyebutnya berbohong. Ibn Katsir, Tafsir al-Quran al-'Adzim..., Jilid 9, 167. Dalam Tarikh al-Thabari disebutkan bahwa Musa bin Misya adalah paman dari Yusa' bin Nun. Keduanya adalah cucu Nabi Yusuf a.s dan hidup sebelum masa Nabi Musa bin Imron. Ahli Taurat menduga, Musa yang pertamalah yang berkenaan dengan kisah Khidir. al-Thabari, Tārīkh al-Thabari..., 364 dan 367

92 Kedirajaan Mesir kuno terdiri dari 31 dinasti dalam rentang waktu dari 3110 SM hngga 30 SM. Firaun berarti firah, yaitu penguasa gedung besar. Nama yang dipercayai sebagai firaun di masa Nabi Musa, yaitu Ramses II (atau Usermare Ramesses II, Ramesses yang Agung). Nama terakhir ini banyak dicatat sebagai firaun yang dimaksud dalam kisah Nabi Musa. Ramses II merupakan firaun Mesir kuno ke2 yang dikenal terlama memegang tampuk kekuasaan selama 67 tahun dengan 170 orang anak dari banyak istri. Ramses II menjadi firaun sejak usia 25 tahun pada tahun 1290 hingga 1223 SM. Adapun firaun terlama duduk sebagai raja adalah Pepi II (Neferkare) dengan masa jabatan selama 90 tahun (2272-2182 SM).

Ramses II dikenal sebagai penguasa yang cakap, penuh ambisi, dan kejam. Ia mampu menaklukkan kembali beberapa daerah yang sempat labil pada masa ayahnya, Seti I (1303-1290). Di samping itu, ia berselera pada arsitektur bangunan yang megah, kukuh, dan indah. Ramses II membuat patungnya sendiri di kuil Thebes yang kini menjadi makamnya dalam bentuk yang menunjukkan betapa ia ingin diketahui sebagai yang agung. Patung itu tingginya 17 meter. Bahkan yang lebih besar lagi yaitu setinggi 19,5 meter terletak di kuil Ramses II di Abu Simbel sebanyak empat buah. Tidak mengherankan bila Nabi Musa sempat kuatir ketika mendapatkan perintah menghadapi firaun. Dedy Suardi, Fir'aun Kontemporer, (Remaja Rosdakarya : Bandung, 1997), 30\&70

${ }^{93}$ http://www.harunyahya.com/indo/buku/kaumkaum008.htm yang direkam pada 13 Okt 2007 13:55:22 GMT.
} 
Firaun tidak saja membuat orang Israel hina, tapi juga mengarahkan orang Mesir untuk tidak menghargai mereka. ${ }^{44}$

Meski tidak sebanyak perbedaannya, ada juga kesamaan elemen-elemen kisah Musa dalam PL dan al-Quran. Dalam beberapa segmen, gambaran dalam PL identik dengan gambaran dalam alQuran, contoh Kel. 2:4 dan 2:7 dengan Q.S al-Qashash 28:11-12 tentang peran kakak Musa mengawal bayi Musa hanyut di sungai hingga menyarankan puteri Firaun menyusukan bayi yang ditemukannya kepada orang yang tepat yang tak lain ibu Musa sendiri. Kel. 2:13 dan 2:14 sama dengan Q.S al-Qashash 28: 19 tentang keinginan Musa untuk melerai dua orang (Ibrani) yang bertengkar. Kel. 3:5 sama dengan Thaha 20:12 tentang perintah Allah agar Musa melepas terompahnya di bukit Horeb. Bandingkan juga Kel. 4:2 dan 4:3 dengan Thaha 20:17-21 tentang mukjizat tongkat Musa. Tuhan berfirman kepadanya: "Apakah yang di tanganmu itu?" Jawab Musa: "Tongkat ". Firman Tuhan: "Lemparkanlah itu ke tanah." Dan ketika dilemparkannya ke tanah, tongkat itu menjadi ular, sehingga Musa lari ketakutan.

\section{Penutup}

Kisah Musa dalam al-Quran tetap runtut meskipun untuk melihat alurnya harus melakukan konfirmasi (munāsabah) antar ayat dalam berbagai surat agar tidak terbalik-balik membaca alur yang semestinya. Misal, momen Thur Sinai yang terjadi dua kali: pertama, ketika Nabi Musa menerima mukjizat dan perintah menghadapi Firaun. Kedua, ketika Nabi Musa menerima kitab Taurat.

Harus ditekankan bahwa Al-Quran memiliki "maksud" sendiri dalam menceritakan kisah-kisahnya termasuk kisah Nabi Musa,95 yaitu berkisah dengan muatan moralitas dan keagamaan yang

\footnotetext{
${ }^{94}$ Mazheruddin Shiddiqi, Konsep Qur'an tentang Sejarah, (Pustaka Firdaus:Jakarta, 1986), 99

${ }_{95}$ Muhammad Abduh sempat berkomentar cukup "ekstrem" dalam al-Manar juz 2 hlm. 20 bahwa sebenarnya tidak ada kisah (fakta sejarah) dalam al-Quran. Yang ada adalah tanda-tanda kebesaran Allah, pelajaran, dan hikmah yang tersirat dengan menggunakan media kisah sebagai bekal berjuang bagi Rasulullah SAW. Kisah Musa sendiri dan kaumnya yang bandel-bandel itu menurut az-Zamakhsari dalam alKasysyaf juz 2 hlm. 25 diceritakan kepada Rasulullah agar dapat mengambil hikmah dan tegar berjuang. Muhammad Ahmad Khalafullah, al-Fann al-Qashashi..., 72 dan 83
} 
sublim. Kisah dalam al-Quran adalah media yang diframing hanya untuk menyampaikan pesan-pesan tauhid, kebaikan, dampak prilaku buruk, kebenaran, dan moral yang bermutu. ${ }^{96}$

Sarjana Barat terutama yang Yahudi, mayoritas memiliki pendapat polemis bahwa kisah dalam al-Quran bukan dari Allah, akan tetapi rekonstruksi (reka ulang) Muhammad sendiri berdasarkan cerita yang didengarnya dari para rahib dan pendeta di Mekah, Medinah, atau Syam saat mengikuti Abu Thalib berdagang. ${ }^{97}$ Sarjana Barat menguatkan tuduhan dengan bukti bahwa al-Quran salah kutip tentang Maryam saudari Harun (Ya ukhta Harun, Q.S Maryam 19:28) sebagai ibu Nabi Isa. Menurut Qadhi Abd al-Jabbar, yang disebut Harun itu bukan Harun saudara Musa tetapi Harun yang lain, karena satu nama tidak selalu merujuk pada satu orang. ${ }^{98}$

Ketimpangan alur kisah juga banyak ditemukan dalam Bibel. Kejujuran bertutur ala Bibel yang tragedik terhadap tokoh-tokoh kisahnya, tidak membantu kita memahami logika kejujuran itu kecuali memperjelas kejanggalannya. Bibel tidak segan-segan mengorbankan kehormatan Nabi-Nabi mereka dalam kisah-kisahnya tanpa dapat ditauladani. Sebaliknya dalam al-Quran, para Nabi dikisahkan dengan terhormat karena mereka memang sosok-sosok pilihan Allah. Kisah-kisah dalam al-Quran menceritakan ketangguhan-ketangguhan moral, mental, dan spiritual para Nabi. Kisah-kisah yang memotivasi dan memantapkan semangat dakwah Nabi (Q.S Hud 11: 120).

\section{DAFTAR PUSTAKA}

Al-Quran al-Karim, cet. Dar el-Ma'rifah, Damaskus, Syria, 1999

Imad al-Din Abu al-Fida' Ismail bin Katsir al-Dimasyqi, Tafsìr alQuran al-'Adzìm, Jilid 9, (Beirut: Maktabah al-Nûr al-Ilmiyah, 1992)

Muhammad Ahmad Khalafullah, al-Fann al-Qashashi fi al-Quran alKarim, (Sina: London-Beirut-Kairo, 1999)

\footnotetext{
${ }^{96}$ Muhammad Qutb, al-Qishshah fi al-Quran..., 169 dan 421

${ }_{97}$ Attihami Naqrah, Sikulujiyat al-Qishshah fi al-Quran..., 61

98 Muhammad Ahmad Khalafullah, al-Fann al-Qashashi..., 57-58
} 
Syukron Affani

Attihami Naqrah, Sikulujiyat al-Qishshah fi al-Quran, (Seri Desertasi: Universitas al-Jazair, 1971)

Muhammad Qutb, al-Qishshah fi al-Quran: Maqāshid al-Dìn wa Qiyām al-Fann, (Dar Qubba': Kairo, 2002)

Manna' Al-Qatthan, Mabâhits fi Ulûm al-Quran, (Riyadh: Mansyûrât al'Âshr al-Hadîts, 1973)

Abu Ja'far Muhammad bin Jarir al-Thabari, Tārikh al-Thabari: Tārìkh alRusul wa al-Muluk, Jilid 1, Cet. II, (Dar al-Ma'arif: Mesir, tth)

Abu al-Faraj Abdurrahman bin Ali bin Muhammad bin Ibn al-Jauzi, al-Muntadzam fi Tārīkh al-Muluk wa al-Umam, Jilid 1, (Dar alKutub al-Ilmiyah: Beirut, 1992)

Syauqi Abu Khalil, Athlas al-Quran, (Dar al-Fikr: Damaskus, 2003)

Yahya C. Staquf, Catatan atas Catatan, Kompas/2/1/08

Dedy Suardi, Fir'aun Kontemporer, (Remaja Rosdakarya : Bandung, 1997)

Mazheruddin Shiddiqi, Konsep Qur'an tentang Sejarah, (Pustaka Firdaus:Jakarta, 1986)

Muzaffaruddin Nadvi, Sejarah Geografi al-Quran, (Pustaka Firdaus:Jakarta, 1997)

M. Faisol, "Interpretasi Kisah Nabi Musa Perspektif Naratologi alQuran" dalam Jurnal ISLAMICA: Jurnal Studi Keislaman, Vol. 11, No. 2, Maret 2017

http://www.harunyahya.com/indo/buku/kaumkaum008.htm yang direkam pada 13 Okt 2007 13:55:22 GMT.

http://jcsm.org/StudyCenter/indo/keluaran_34.html yang direkam pada 13 Des 2007 09:56:27 GMT.

http://www.gkipi.org/files/bible_tks/041209.htm yang direkam pada 8 Des 2007 18:48:13 GMT.

Richard L. Strauss, Hal Terpenting, dalam

http:// www.bible.org/page.php?page_id=3728 yang direkam pada 15 Des 2007 05:26:19 GMT

http:// www.bible.org/page.php?page_id=3672 yang direkam pada 15 Des 2007 05:48:04 GMT.

Software DivineIslam's Qur'an Viewer software v2.913 by Jamal

Nashir

Software Digital Quran ver.3.2 tahun 2003-2004 by Sony Sugema

Software Program alKitab v. 2.7 (1999-2000) by 